\title{
FOUR-PART FRACTURES OF THE NECK OF THE HUMERUS
}

\author{
P. G. STABLEFORTH
}

From the Bristol Royal Infirmary

\begin{abstract}
Four-part fractures of the upper end of the humerus are uncommon injuries and there is still dispute about the best form of management. A retrospective study of 32 patients with these injuries has shown that non-operative management is frequently followed by persistent pain, stiffiness and dysfunction of the shoulder. A prospective study of 49 patients with this injury presenting at the Bristol Royal Infirmary has shown that reconstruction of the upper end of the humerus with insertion of a Neer prosthesis will usually restore comfort and function. Whichever regimen is employed, disability is prolonged and dedicated physiotherapy is essential in their management.
\end{abstract}

It is now some 13 years since Dr Charles Neer published his classification of fractures of the upper end of the humerus and described his experience with prosthetic replacement of the proximal articular surface of the humeral head for displaced four-part fractures (Neer 1970a, b). Previously, Richard, Judet and Rene (1952) and de Anquin (1967) had reported on the use of a similar prosthesis. Subsequently, however, there has been an unenthusiastic report by Kraulis and Hunter (1977). This paper presents a study of 81 patients with four-part fractures (Figs 1 to 6) undertaken to identify the complications and long-term problems of non-operative treatment and define the place of primary surgical reconstruction with insertion of a Neer humeral head prosthesis.

\section{PATIENTS}

Eighty-one patients with four-part fractures of the proximal humerus have been examined. Thirty-two were reviewed retrospectively and a further 49 patients, all consecutive referrals to our unit in the Bristol Royal Infirmary over the last 12 years, formed the prospective study group. The age, sex and arm dominance of the patients are set out in Table I. Eighty-five per cent of patients were between 51 and 80 years, and only three patients under 50 years old.

Initial complications of injury. There were no deaths from injury. Two patients died within three months and a further four are known to have died within one year. Thirteen of the 81 patients had associated injuries which affected primary management.

Vascular injuries (4.9 per cent). One patient required above-elbow amputation for gangrene after rupture of an axillary vessel. One patient, whose detached humeral

P. G. Stableforth, FRCS, Consultant Orthopaedic Surgeon Orthopaedic and Accident Unit, Bristol Royal Infirmary, Bristol BS2 8HW, England.

(C) 1984 British Editorial Society of Bone and Joint Surgery $0301-620 X / 84 / 1003 \$ 2.00$ head entered the pleural cavity, needed transfusion and ligation of the third and fourth intercostal vessels to control hypovolaemic shock. In two patients an atherosclerotic vessel was ruptured: in one the vessel was repaired, while the other was treated non-surgically; both recovered satisfactorily.

Brachial plexus damage (6.1 per cent). Five patients had injuries of the nerves of the brachial plexus: in three both the median and ulnar nerves were injured and in two the median nerve alone. Signs of nerve damage were delayed for 24 hours in two of them. Two of these patients made a full recovery; three made an incomplete recovery, no improvement in their function being seen more than two years after the injury.

Table I. Four-part fractures of the upper humerus

$$
\begin{aligned}
& \text { Total : } 81 \text { patients } \\
& \text { Sex : } 20 \mathrm{M}: 61 \mathrm{~F} \\
& \text { Age : } 29-92 \text { years (mean } 67 \text { years) } \\
& \text { Side : } 48 \text { dominant : } 33 \text { non-dominant }
\end{aligned}
$$

Chest wall damage ( 2.5 per cent). Two patients with fracture-dislocations had fractured their second, third and fourth ribs and developed a pneumothorax. The humeral head remained subcoracoid in one and lay free in the pleural cavity of the other patient. Both recovered fully from the chest injury.

Associated injuries (3.7 per cent). Three patients had Colles' fractures of the same wrist. All three united rapidly and left the patients with no functional disability.

\section{TREATMENT AND RESULTS}

\section{Retrospective study}

Thirty-two patients were re-examined five to fourteen years after injury. 
Initial treatment was either manipulative or operative. Manipulation. In 13 patients with a disorganised upper end of humerus but without dislocation, manipulation produced no permanent improvement in fracture position. In 13 patients with a fracture and subcoracoid dislocation, manipulation achieved acceptable fracture position in three, but one fracture had redisplaced two weeks from injury. Satisfactory fracture union occurred toilet care, dressing and assistance with eating; nine further patients needed some help with the activities of daily living. Two patients developed crippling hand stiffness and two made an incomplete recovery from brachial plexus damage and were also left severely disabled. Only one patient was free of pain; 21 had sleep disturbance, 17 took analgesics regularly and one patient's life was dominated by shoulder pain.
"UNDISPLACED" 4 PART FRACTURE

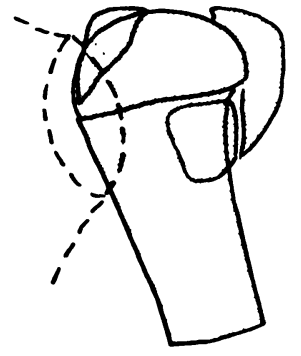

Fig. 1

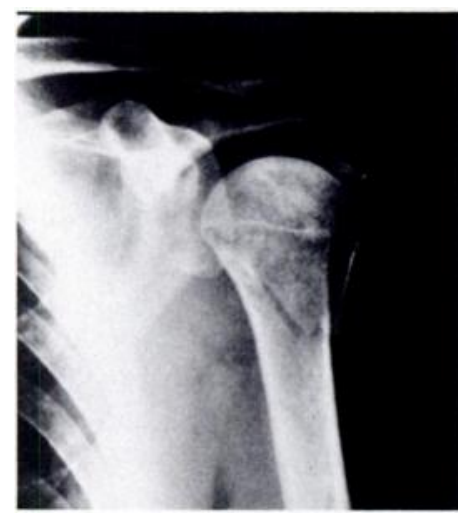

Fig. 4
SUBCORACOID FRACTURE DISLOCATION

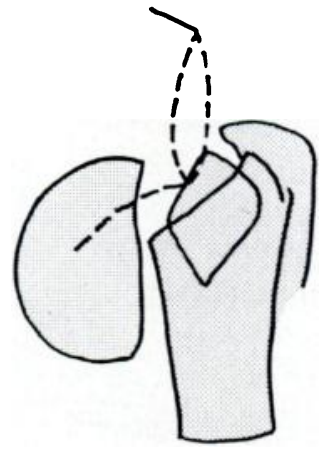

Fig. 2

\section{ROTATION FRACTURE DISLOCATION}

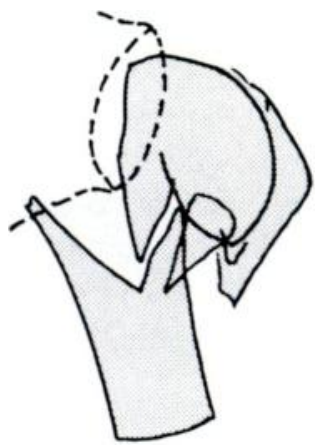

Fig. 3

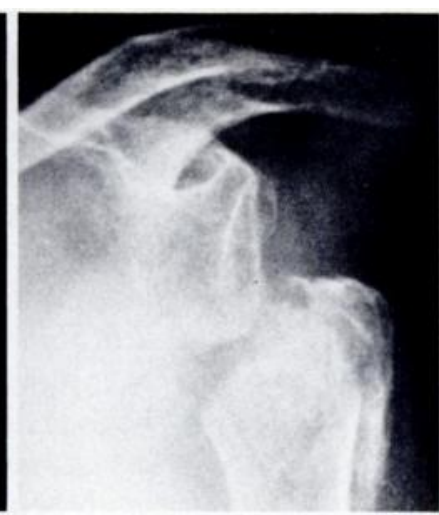

Fig. 5

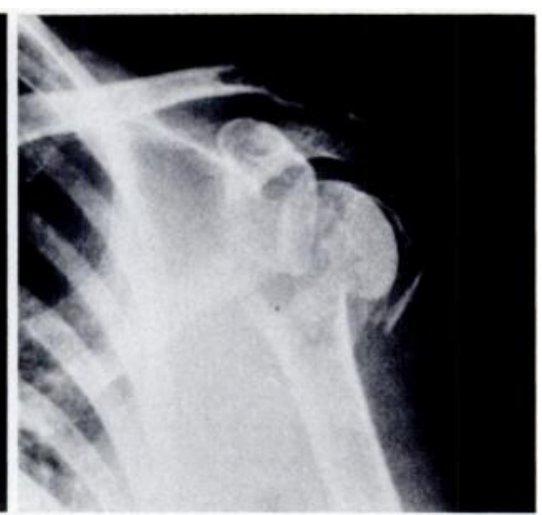

Fig. 6

Line drawings and radiographs of the three sub-types of fracture.

in two patients: one was pleased with her shoulder function until her death five months from injury, whilst the second developed increasing pain and stiffness as a consequence of avascular necrosis 12 months from injury. Surgical treatment. In three patients primary open reduction was performed but internal fixation not used; all fractures redisplaced. In five patients with fracturedislocations the axilla was explored as pressure by the humeral head was thought to be the cause of brachial plexus damage. Full neurological recovery occurred in four of the five patients, including one whose humeral head was left amongst the nerves of the plexus.

Results. Twenty-nine of the 32 patients had unsatisfactory results (Table II).

Subjective assessment. Seven patients, all with injury to the dominant arm, were totally dependent on others for
Radiographic appearance. Twenty-three fractures had united. In seven patients the fracture fragments were in acceptable but not in anatomical position; in 16 the humeral head was malrotated and the tuberosities displaced. Three patients had bony glenohumeral fusion and four humeral heads showed avascular necrosis.

\section{Prospective study}

All patients referred to the Bristol Royal Infirmary between 1970 and 1981 with a four-part humeral fracture have been studied. Those patients whose fracture appeared "impacted" and little displaced have been treated conservatively; those whose radiograph showed a disorganised upper end of humerus or displacement of the detached humeral head into the axilla have been assigned by pre-arranged random selection for upper 
humeral reconstruction with insertion of a Neer prosthesis, or for non-surgical management. No patient was withdrawn from the study on account of age or medical condition and no patient to whom surgery was recommended refused operation.

All operations were performed by the same surgeon within five days of injury. The shoulder was exposed through the deltopectoral approach and the anterior part of the deltoid was detached from the clavicle to expose the biceps tendon and groove. The tuberosities were defined and retracted, the upper humeral shaft trimmed to receive the prosthesis which was gently impacted without cement fixation in 40 degrees of retroversion (Figs 7 and 8). The tuberosities were reattached through drill holes in the upper humeral shaft or through the holes in the prosthesis with wire or braided nylon sutures to restore the cuff muscles to their correct tension; after assessment of shoulder stability and mobility the deltoid was carefully reattached by nylon sutures passed through drill holes in the clavicle.

Table II. Functional results of non-operative treatment of displaced four-part fractures (32 patients)

\begin{tabular}{|lr|}
\hline Actirities of daily living & 7 \\
Total dependence & 9 \\
Need help & 16 \\
Independent & \\
Pain & 18 \\
Regular analgesics & 21 \\
Sleep disturbed by pain & 1 \\
Pain free & \\
Functional mohility & 6 \\
Hand to mouth & 1 \\
Hand to buttock & 25 \\
Hand neither to mouth nor buttock & \\
\hline
\end{tabular}

All patients, in both groups, had the forearm and elbow supported in a sling in a little abduction and flexion. Immediate use of the hand was encouraged, shoulder flexion and rotation exercises started after two or three days, but abduction was not attempted until four weeks had elapsed. All patients continued supervised physiotherapy for three to six months and were seen regularly for assessment of pain, functional disability, shoulder mobility and strength.

Results. Seventeen of the 49 patients had minimally displaced fractures and 32 had fractures with severe displacement. Their age, sex and arm dominance are set out in Table III.

Displaced fracture group. Sixteen patients have been operated upon and 16 have been managed non-operatively. Two patients died, one two months postoperatively

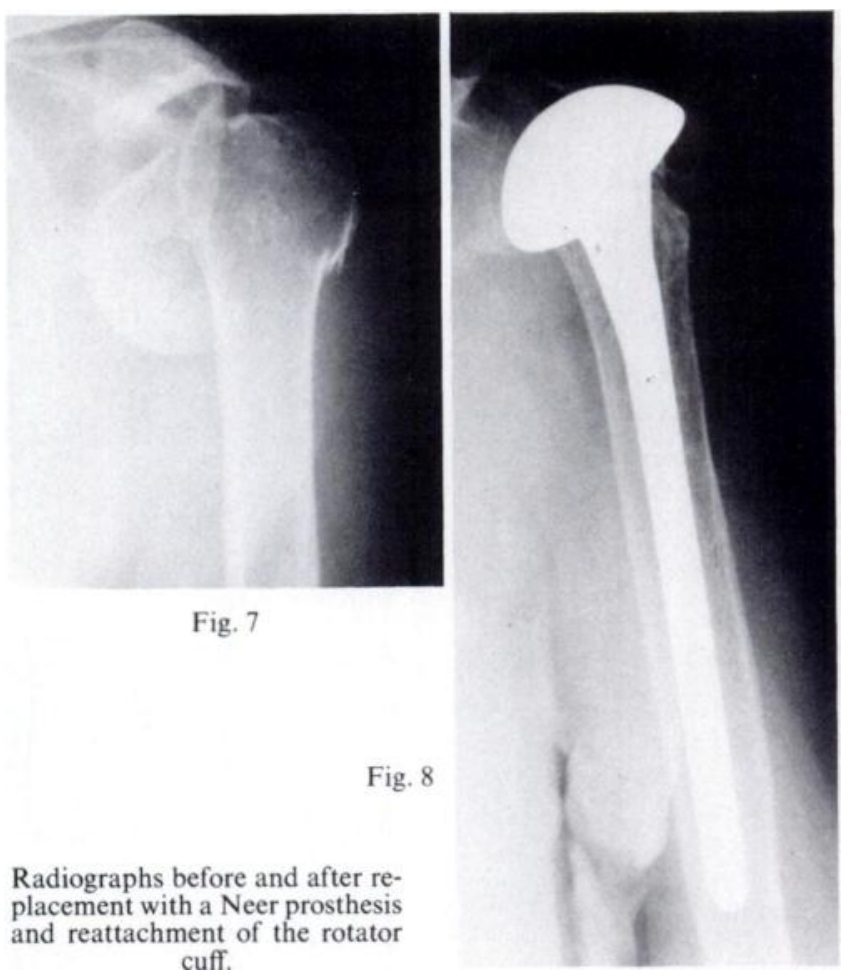

and one unoperated patient three months from injury, both from causes unrelated to their fracture. The rest have been reviewed between 18 months and 12 years from injury.

Two patients developed haematomata after operation: one resolved, the other developed an associated cellulitis which resolved initially with antibiotic therapy but the prosthesis had subsequently to be removed because of continuing sepsis. Stiffness of the elbow was a common initial problem but did not persist in any patient.

The final range of movements is set out in Table IV. As can be seen the surgically treated group had consistently better range of movements than those treated non-operatively, with 11 patients regaining over 90 degrees of flexion and 15 of the 16 being able to place the hand behind the buttock to attend to toilet needs; by contrast only one patient managed non-operatively regained 90 degrees of flexion and only eight of the 16 patients regained functionally adequate medial rotation.

The surgical patients made a fuller functional

Table III. Prospective study of 49 patients

\begin{tabular}{|c|c|c|c|}
\hline & \multicolumn{2}{|l|}{ Displaced } & \multirow[b]{2}{*}{ Impacted } \\
\hline & Neer prosthesis & Non-operative & \\
\hline Total & 16 & 16 & 17 \\
\hline Age & $\begin{array}{l}52.88 \\
\text { (65.6 years) }\end{array}$ & $\begin{array}{l}60-85 \\
\text { (70.1 years) }\end{array}$ & $\begin{array}{l}58-80 \\
(67.7 \text { years })\end{array}$ \\
\hline Sex & $\begin{array}{l}4 \text { male } \\
12 \text { female }\end{array}$ & $\begin{array}{l}3 \text { male } \\
13 \text { female }\end{array}$ & $\begin{array}{l}3 \text { male } \\
14 \text { female }\end{array}$ \\
\hline Side & $\begin{array}{l}10 \text { dominant } \\
6 \text { non-dominant }\end{array}$ & $\begin{array}{l}11 \text { dominant } \\
5 \text { non-dominant }\end{array}$ & $\begin{array}{l}10 \text { dominant } \\
7 \text { non-dominant }\end{array}$ \\
\hline
\end{tabular}


Table IV. Prospective study: range of movement

\begin{tabular}{|lcc|}
\hline & Prosthesis (16) & Non-operative (16) \\
\hline Flexion & 11 & 1 \\
Over 90 degrees & 1 & 7 \\
Under 45 degrees & \\
Medial rotation & 15 & 8 \\
Thumb to T12 spinous & 15 \\
process & & \\
Lateral rotation & 8 & 2 \\
Over 25 degrees & 2 & 10 \\
Under 5 degrees & 2 & \\
\hline
\end{tabular}

Table V. Prospective study: functional results

\begin{tabular}{|lll|}
\hline & $\begin{array}{l}\text { Prosthesis } \\
(\mathbf{1 6 )}\end{array}$ & $\begin{array}{l}\text { Non-operative } \\
(\mathbf{1 6 )}\end{array}$ \\
\hline $\begin{array}{l}\text { Independent for activities of } \\
\text { daily living at six months }\end{array}$ & 14 & 7 \\
Pain & & \\
None or occasional & 11 & 3 \\
Constant (severe in some cases) & 2 & 9 \\
Power & & \\
Flexion & 12 & 8 \\
Abduction & 10 & 6 \\
Lateral rotation & 14 & 8 \\
\hline
\end{tabular}

* Power: number of patients regaining 75 per cent of the strength of the uninjured side

recovery (Table V). Seven were independent for the activities of daily living at three months and all but two at six months; less than half of the non-surgical patients were fully independent at six months. Nearly all patients in both groups had shoulder pain, but loss of sleep and functional disability due to pain was more common in the non-surgical group. Return of shoulder strength was also more certain after operation.

Minimally displaced fracture group. The 17 patients with

Table VI. Impacted four-part fractures: result of conservative management in 17 patients

\begin{tabular}{|lr|lr|}
\hline Movement & & Function \\
\hline $\begin{array}{lrl}\text { Flexion } \\
\text { Over 90 degrees }\end{array}$ & 11 & $\begin{array}{l}\text { Independent for activities of } \\
\text { daily living by 6 months }\end{array}$ & 11 \\
Under 45 degrees & 2 & & \\
$\begin{array}{l}\text { Medial rotation } \\
\text { Beyond T12 }\end{array}$ & 15 & $\begin{array}{l}\text { Pain } \\
\text { None or occasional }\end{array}$ & 6 \\
Constant & 2 \\
$\begin{array}{l}\text { Overal rotation } 25 \text { degrees } \\
\text { Under 5 degrees }\end{array}$ & 4 & $\begin{array}{l}\text { Power } \\
75 \text { per cent of sound side }\end{array}$ & 7 \\
\hline
\end{tabular}

impacted four-part fractures were managed non-operatively. The results of their treatment were very similar to those of displaced fractures treated operatively, as can be seen from Table VI.

\section{DISCUSSION}

Although four-part fractures and fracture-dislocations constitute only two per cent of adult upper humeral fractures this study supports the conclusion of Neer and others (Knight and Mayne 1957; Neer 1970a, b; Clifford 1981) that shoulder stiffness is common, pain persistent and functional disability usual after non-operative treatment.

As most patients were elderly and made fairly limited demands on their shoulders I have used a simple assessment of results based on restoration of function, not employing the comprehensive assessment introduced by Neer (Neer 1970a). All patients in the study had imperfect results, but comfort and strength were vital and medial rotation and elevation in flexion more useful than abduction.

This study has shown that closed manipulation has not been satisfactory, probably as a consequence of the severe soft-tissue disruption and detachment of the humeral head. A number of reconstructive procedures have been described; those in which the humeral head is retained often fail when the head later collapses from avascular necrosis (Laing 1956; Knight and Mayne 1957; Rosen 1973) whilst reattachment of the cuff after removal of the humeral head usually results in poor function of the shoulder (Jones 1942; Knight and Mayne 1957). The Neer reconstruction with prosthetic replacement of the detached humeral head and reattachment of the rotator cuff muscles would thus seem logical.

The operation is not difficult, although the rotator cuff tendons and attached tuberosities need careful definition and elevation and their replacement at correct tension needs judgement; reattachment of the cuff is often made easier if the arm is held in a little flexion and rotation to relax the cuff as the sutures are tied.

It is my experience that pre-existing tears or degenerative disease of the rotator cuff tendons have rarely been a problem in these primary reconstructions though subsequent cuff rupture has marred the late result in one patient. Inferior subluxation of the prosthesis has been usual in the first three or four weeks despite a sling supporting the elbow but has resolved as muscle tone has recovered.

Remobilisation of the shoulder after these severe fractures is always slow and taxing and the vital contribution of a skilled and dedicated physiotherapist cannot be overemphasised. Three or four months of intensive remobilisation may be necessary before these elderly patients can undertake the activities of daily living without help; as improvement in mobility may continue for 12 to 18 months, mental alertness and determination have proved more important than age or 
physique. This may perhaps explain the poor results described by Kraulis and Hunter (1977) in their patients, who were sometimes uncooperative. Where a mentally alert patient is admitted to a centre with facilities for reconstructive shoulder surgery and prolonged physiotherapy, the Neer reconstruction of the upper end of the humerus appears to have clear advantages in these severe but uncommon injuries.

\section{REFERENCES}

Clifford PC. Fractures of the neck of the humerus: a review of late results. Injury 1981;12:91-5.

de Anquin CE. Substitution par prothèse de la tête humérale. Chirurgie orthopédique et de traumatologie: 10ème congrès de SICOT. Bruxelles: Acta Medica Belgica, 1967:731-8.

Jones L. The shoulder joint -observations on the anatomy and physiology: with an analysis of a reconstructive operation following extensive injury. Surg Gynecol Obstet 1942;75:433.

Knight RA, Mayne JA. Comminuted fractures and fracture-dislocations involving the articular surface of the humeral head. J Bone Joint Surg $[\mathrm{Am}]$ 1957:39-A:1343-55.

Kraulis J, Hunter G. Results of prosthetic replacement in fracture dislocations of the upper end of the humerus. J Bone Joint Surg [Br] 1977; 59-B: 508 .

Laing PG. Arterial supply of the adult humerus. J Bone Joint Surg [ Am] 1956;38-A: 1105-16.

Neer CS II. Displaced proximal humeral fractures. Part I: classification and evaluation. J Bone Joint Surg [Am] 1970a;52-A : $1077-89$.

Neer CS II. Displaced proximal humeral fractures. Part II : treatment of three-part and four-part displacement. J Bone Joint Surg [Am] 1970b; 52-A: 1090-103.

Richard A, Judet R, Rene $\mathbf{L}$. Reconstruction prothétique acrylique de l'extrémité supérieure de l'humérus spécialement au cours des fracturesluxations. J Chir 1952;68:537-47.

Rosen H. Tension band wiring for fracture dislocations of the shoulder. Chirurgie orthopédique et traumatologie: I2ème congrès de SICOT. Amsterdam: Excerpta Medica, 1973:939-41. 